\title{
DESEMPENHO DE BOVINOS DE CORTE NO PASTO SUPLEMENTADOS COM MISTURAS MÚLTIPLAS CONTENDO URÉIA E AMIRÉIA
}

\author{
Performance of grazing beef cattle supplemented \\ with multiple mixtures containing urea and amireia
}

\author{
Clenderson Corradi de Mattos Gonçalves ${ }^{1}$, Júlio César Teixeira², Antônio Ricardo Evangelista ${ }^{2}$, \\ Juan Ramón Olalquiaga Pérez², Joel Augusto Muniz ${ }^{3}$
}

\begin{abstract}
RESUMO
O presente trabalho foi realizado com o objetivo de avaliar o real potencial da amiréia $150 \mathrm{~S}$ comparada com mistura equivalente em uréia, milho moído e flor de enxofre, como ingredientes em misturas múltiplas para bovinos de corte no pasto. Foram utilizados 40 bezerros sem raça definida, com peso médio de $167 \mathrm{Kg}$, no período das águas, e 40 bezerros sem raça definida, com peso médio de $285 \mathrm{Kg}$, no período seco. Os tratamentos foram baseados na amiréia $150 \mathrm{~S}$ e mistura equivalente em milho moído, uréia e flor de enxofre com núcleo mineral e sal, sendo esse em dois níveis para regular consumo. As misturas formuladas foram amiréia com 8,75\% de sal (AM-8,75), uréia com 8,75\% de sal (UR-8,75), amiréia com 17,50\% de sal (UR17,50) e uréia com 17,50\% de sal (UR-17,50). O delineamento experimental utilizado foi em blocos casualizados com repetição dentro dos blocos experimentais. Avaliaram-se o desempenho e o consumo das misturas dos animais nas fases das águas e seca. Não foi encontrada diferença para ganho de peso (GP) e ganho de peso médio diário (GPMD) entre os tratamentos na fase das águas, na qual se pôde observar uma melhor qualidade da forragem nos piquetes. No período seco, quando a qualidade do capim foi inferior à do período das águas, houve diferença significativa para GP e GPMD, ou seja, observaram-se melhores desempenhos para os animais que receberam misturas com amiréia $150 \mathrm{~S}$ do que para os animais que receberam misturas com uréia.
\end{abstract}

Termos para indexação: Amido, amiréia, bovino corte, Brachiaria brizantha, extrusão, mistura múltipla, uréia.

\begin{abstract}
The present work was carried out with the objective to evaluate the real potential of the amireia 150S compared with equivalent mixture with urea, corn ground and sulfur flower as ingredients in multiple mixtures for grazing beef cattle. It was used 40 calves without defined breed with average weight of $167 \mathrm{Kg}$ in the raining season and 40 calves without defined breed with average weight of $285 \mathrm{Kg}$ in the dry season. The animals were distributed in paddocks of Brachiaria brizantha cv. Marandu and were separated by electrified fence and each paddock possessed covered hod and individual drinking fountain. The treatments were based in the amireia $150 \mathrm{~S}$ and equivalent mixture with ground corn, urea and sulfur flower with mineral nucleus and salt being these two levels used to regulate consumption. The formulated mixtures were amireia with $8.75 \%$ of salt (AM - 8.75), urea with $8.75 \%$ of salt (UR - 8.75), amireia with $17.5 \%$ of salt (UR - 17.50) and urea with $17.5 \%$ of salt (UR 17.50). The experimental design used was randomized blocks with repetition inside; the 40 animals of each phase were divided in 5 blocks in function of the initial weight and then they were allocated randomly in the 4 paddocks where the animals received the treatments at random. It was evaluated the performance and consumption of the mixtures offered to the animals in the raining and dry seasons. It was not found significant difference for weight gain (GP) and average daily weight gain (GPMD) among the treatments in the raining season in which a better quality of the forage can be observed in the paddocks. In the dry season where the grass quality was inferior when compared to that of the raining season there was significant difference for GP and GPMD in which was observed best performance for the animals who received mixtures with amireia $150 \mathrm{~S}$ in relation to the animals that received mixtures with urea.
\end{abstract}

Index terms: Starch, amireia, beef cattle, Brachiaria brizantha, extrusion, multiple mixture, urea.

(Recebido para publicação em 16 de abril de 2003 e aprovado em 6 de agosto de 2003)

\section{INTRODUÇÃO}

O Brasil possui o maior rebanho comercial do mundo, com 166.847 milhões de cabeças, ocupando a segunda posição na produção de carne, com 7.322 milhões de toneladas (ANUALPEC, 2002). A produção de bovinos de corte no Brasil está diretamente relacionada à utilização de pastagens.

A utilização de fontes alternativas de proteína na produção de bovinos é importante, e a uréia destacase como fonte de nitrogênio não-protéico bastante utilizada na alimentação de ruminantes, apesar de 
sofrer limitações em razão de sua baixa aceitabilidade pelos animais, sua segregação quando misturada com outros ingredientes e sua alta toxidade, que é agravada pela elevada solubilidade no rúmen.

A mistura sal-uréia-mineral é útil na mantença de animais e constitui um método simples e econômico a ser usado quando se busca a adaptação dos bovinos ao uso da uréia, quando o sistema prevê o uso mais intensivo desse suplemento em alguma fase do sistema de produção. Suplementos múltiplos de baixo consumo, contendo níveis elevados de sal e uréia, são indicados quando se desejam ganhos na faixa de 200 a 300g/animal/dia (PAULINO, 1999).

Os complexos de liberação lenta de uréia, como a amiréia, podem reduzir toxidade potencial e melhorar aceitabilidade e utilização de concentrados à base de uréia (OWENS, 1980). Como forma de viabilizar a utilização da uréia, pesquisas têm sido conduzidas com o intuito de desenvolver produtos que possam ser mais bem utilizados por ruminantes, como a starea (STILES, 1970; BARTLEY e DEYOE, 1975), desenvolvida pela Universidade do Kansas mediante processamento do grão, juntamente com uréia, por extrusão (HELMER, 1970a).

O produto decorrente do tratamento prévio da uréia com fontes de amido pelo processo de extrusão fornece energia disponível aos microrganismos do rúmen, ao mesmo tempo em que a uréia é hidrolisada em amônia, provendo, simultaneamente, os principais componentes para a síntese de proteína microbiana (HELMER, 1970b; BARTLEY e DEYOE, 1975; MHURER et al., 1986). Nesse processo, o grão de amido é gelatinizado e a uréia, que originalmente está na forma cristalina, passa para a forma não-cristalina. Após sofrer modificação na sua estrutura, a uréia está menos disponível ao ataque da urease bacteriana em relação à sua forma original e ao amido gelatinizado resulta em um produto mais fermentável, o qual reduz o $\mathrm{pH}$ do rúmen.

Conseqüentemente, é mais lenta a absorção da amônia e menor sua concentração no sangue, reduzindo os riscos de toxidez (BARTLEY e DEYOE, 1975).

De acordo com Maia et al. (1987) e Teixeira (1987), a amiréia poderia trazer benefícios à alimentação de ruminantes, possibilitando a sua inclusão na dieta em razão do seu baixo custo e do alto valor protéico. Seu valor nutricional já está comprovado na utilização em dietas concentradas, além da possibilidade de seu emprego com mistura de sal mineral para animais em regime de pasto, visando a melhorar a utilização do ni- trogênio, como uréia pelos ruminantes. Além disso, esse tipo de produto apresenta melhores características de manuseio, produzindo excelentes misturas ao ser incorporado na ração, uma vez que, pelo processo de extrusão, ocorre redução no alto teor de higroscopicidade produzido pela uréia (BARTLEY e DEYOE, 1975).

A presente pesquisa foi conduzida com o objetivo de avaliar o real potencial da amirea $150 \mathrm{~S}$, comparada com mistura equivalente em uréia, milho moído e flor de enxofre como ingredientes em misturas múltiplas para bovinos de corte em pasto.

\section{MATERIAL E MÉTODOS}

O presente trabalho foi realizado na Fazenda Taboão, localizada no município de Bom Sucesso e às margens do Rio Grande.

A área experimental, com 25,84 hectares, coberta uniformemente por Brachiaria brizantha cv. Maran$\mathrm{du}$, foi redividida, após levantamento topográfico, em quatro piquetes de 6,46 hectares, por meio de cerca electrificada por bateria com carregador solar. Foram instalados bebedouros e comedouros cobertos em cada piquete.

O experimento foi dividido em dois períodos experimentais, sendo fase das águas e fase das secas. A fase das águas teve duração de 155 dias experimentais, entre 12 de setembro de 2001 a 14 de fevereiro de 2002. A fase das secas teve duração de 74 dias experimentais, entre 20 de julho e 2 de outubro de 2002.

$\mathrm{Na}$ fase das águas, foram utilizados 40 bezerros sem raça definida, típicos da região, com peso vivo médio de $167 \mathrm{Kg}$; na fase seca, foram utilizados 40 bezerros sem raça definida, com peso vivo médio de $285 \mathrm{Kg}$.

Foi construído um curral de manejo, rústico, com tronco e gaiola para instalação de uma balança eletrônica móvel, Toledo modelo MGR-2000, para controle de peso dos animais.

Os tratamentos foram baseados na amiréia com equivalente protéico de $150 \%$ (amiréia 150S) e mistura equivalente em milho moído, uréia e flor de enxofre com núcleo mineral e sal, sendo esse em 2 níveis para regular o consumo. As misturas múltiplas formuladas foram Amiréia, com $8,75 \%$ sal (AM-8,75); Uréia, com 8,75\% de sal (UR-8,75); Amiréia, com 17,50\% de sal (AM-17,50) e Uréia, com $17,50 \%$ de sal (UR-17,50), como apresentado na Tabela 1 . 
As misturas múltiplas foram formuladas de modo que a porcentagem de proteína bruta da AM8,75 fosse semelhante a UR-8,75 e a AM-17,50 fosse semelhante a UR-17,50. Já as porcentagens de cálcio, fósforo e enxofre foram semelhantes nas quatro misturas.

As misturas foram fornecidas nos cochos à vontade, para que o consumo fosse regulado pelo próprio animal.

No início e no final de cada fase experimental, foram coletadas amostras de Brachiaria brizantha c.v. Marandu com um quadrado (moldura) com área de 1 $\mathrm{m}^{2}$, sendo, em cada piquete, coletadas 8 amostras simples em pontos aleatórios. Posteriormente, essas amostras foram homogeneizadas em uma amostra composta, a qual foi enviada para o laboratório. Cada amostra simples foi pesada em uma balança do tipo dinamômetro e, posteriormente, foi feita uma média dos pesos por piquete para se determinar a produção de matéria natural por ha.

Os dados da análise bromatológica e disponibilidade da Brachiaria brizantha cv. Marandu nas fases das águas e seca são apresentados na Tabela 2.

As Misturas Múltiplas foram produzidas na Fábrica de Ração do Departamento de Zootecnia da Universidade Federal de Lavras, em que cada lote era amostrado e suas respectivas amostras eram enviadas para o Laboratório de Nutrição, onde foram realizadas as análises.

O consumo das misturas era avaliado de dois em dois dias, pela manhã, por meio da diferença entre a pesagem do alimento fornecido e as sobras deixadas no cocho. Foi utilizada uma balança Filizola de bandeja, com escala de $5 \mathrm{~g}$, para controlar o consumo das misturas.

O desempenho dos animais era avaliado de 14 em 14 dias mediante pesagens individuais, pela manhã.

A disponibilidade da Brachiaria brizantha nos piquetes foi avaliada no início e no final de cada fase pela "Técnica do Quadrado" (AGUIAR e AMARAL, 2001). Após avaliar a produção de matéria natural, amostras do capim foram separadas e enviadas para análises no Laboratório de Nutrição Animal do Departamento de Zootecnia da Universidade Federal de Lavras.

As amostras de capim e das misturas foram levadas para o Laboratório de Nutrição Animal do Departamento de Zootecnia da Universidade Federal de Lavras, onde, depois de serem compostas e devidamente homogeneizadas, foram secas em estufa com circulação forçada de ar regulada a $60^{\circ} \mathrm{C}$, durante 72 horas, para determinação da matéria seca (pesagem a quente). Após essa pesagem, as amostras foram moídas num moinho de faca tipo "WILLY" com peneira de 30 mesh.

Nas amostras moídas de capim e misturas, foram determinadas a matéria seca a $105^{\circ} \mathrm{C}$ e a proteína bruta, segundo metodologias descritas por Association of Official Analytical Chemist (AOAC, 1990). Os minerais foram analisados em espectofotômetro de absorção atômica, segundo Silva (1998). Para determinação da fibra em detergente neutro (FDN) e fibra em detergente ácido (FDA) nas amostras de capim, foram utilizadas as metodologias propostas por Soest (1991).

TABELA 1 - Níveis em \% dos ingredientes nas Misturas Múltiplas.

\begin{tabular}{lcccc}
\hline \multirow{2}{*}{ Ingredientes } & \multicolumn{4}{c}{ Tratamentos } \\
\cline { 2 - 5 } & $\mathbf{A M - 8 , 7 5}$ & UR-8,75 & AM-17,50 & UR-17,50 \\
\hline Amiréia 150S & 43,75 & --- & 35,00 & --- \\
Milho moído & 30,00 & 49,80 & 30,00 & 45,75 \\
Uréia & --- & 23,10 & --- & 18,55 \\
Flor de enxofre & --- & 0,85 & --- & 0,70 \\
N. mineral & 17,50 & 17,50 & 17,50 & 17,50 \\
Sal comum & 8,75 & 8,75 & 17,50 & 17,50 \\
\hline
\end{tabular}

Ciênc. agrotec., Lavras, v. 28, n. 1, p. 174-181, jan./fev., 2004 
TABELA 2 - Composição bromatológica e disponibilidade de Brachiaria no início (DI) e no final (DF) nos períodos das águas e seca.

\begin{tabular}{lcccc}
\hline & \multicolumn{4}{c}{ Tratamentos } \\
\cline { 2 - 5 } & AM-8,75 & UR-8,75 & AM-17,50 & UR-17,50 \\
\hline DI (t MN/ha) & 16,08 & Período Águas \\
DI (t MS/ha) & 4,28 & 18,32 & 18,72 & 15,72 \\
DF (t MN/ha) & 14,28 & 5,41 & 5,18 & 4,21 \\
DF (t MS/ha) & 4,01 & 13,88 & 14,12 & 12,28 \\
MS (\%) & 27,44 & 4,17 & 4,12 & 3,73 \\
PB (\%) & 7,93 & 29,19 & 27,56 & 27,86 \\
FDN (\%) & 73,83 & 7,69 & 8,16 & 7,94 \\
FDA (\%) & 37,76 & 73,40 & 73,19 & 72,90 \\
& & 37,72 & 36,31 & 38,50 \\
\hline DI (T MN/ha) & 10,53 & Período Seco & & 9,60 \\
DI (T MS/ha) & 4,83 & 10,00 & 10,80 & 4,67 \\
DF (T MN/ha) & 8,95 & 4,75 & 4,74 & 5,70 \\
DF (T MS/ha) & 4,70 & 7,38 & 8,20 & 3,32 \\
MS (\%) & 50,74 & 4,50 & 4,67 & 53,50 \\
PB (\%) & 5,32 & 54,35 & 50,40 & 4,18 \\
FDN (\%) & 72,20 & 4,68 & 4,57 & 73,28 \\
FDA (\%) & 42,07 & 74,48 & 74,53 & 43,24 \\
\hline
\end{tabular}

O delineamento experimental utilizado foi em blocos casualizados com repetição dentro, em que os animais foram blocados de acordo com o peso inicial. Os 40 animais em cada fase foram divididos em 5 blocos e sorteados nos 4 piquetes, nos quais receberam 4 tratamentos diferentes ao acaso, ficando 10 animais por piquete distribuídos em 5 blocos com 2 animais.

Pela estrutura dos tratamentos, decidiu-se utilizar a técnica de contraste ortogonais para comparação de médias. Os contrastes organizados foram os seguintes:

$\mathrm{y}_{1}=\mathrm{T}_{1}-\mathrm{T}_{3}$, compara as misturas com amiréia e diferentes níveis de sal $(8,75 \%$ e 17,5\%);

$\mathrm{y}_{2}=\mathrm{T}_{2}-\mathrm{T}_{4}$, compara as misturas com uréia e diferentes níveis de sal $(8,75 \%$ e $17,5 \%)$;

$\mathrm{y}_{3}=\mathrm{T}_{1}-\mathrm{T}_{2}+\mathrm{T}_{3}-\mathrm{T}_{4}$, compara a amiréia com a uréia.
O modelo estatístico foi:

$$
y_{i j k}=\mu+t_{i}+b_{j}+e_{i j k}
$$

sendo:

$\mathrm{y}_{\mathrm{ijk}} \mathrm{O}$ valor observado do animal $\mathrm{k}$ dentro do bloco $\mathrm{j}$ que recebeu o tratamento i;

$\mu$ uma constante;

$t_{i}$ o efeito do tratamento i com $i=1,2,3,4$;

$b_{j}$ o efeito do bloco $\mathrm{j}$ com $\mathrm{j}=1,2,3,4,5$;

$\mathrm{e}_{\mathrm{ijk}} \mathrm{o}$ erro experimental associado a $\mathrm{y}_{\mathrm{ijk}} \operatorname{com} \mathrm{k}=1,2 \mathrm{o}$ número de repetições dentro de cada bloco que, por hipótese, tem distribuição normal de média zero e variância $\sigma^{2}$.

Os dados obtidos foram analisados utilizando-se o software estatístico SAS INSTITUTE (1991), e o pro- 
cedimento GLM (General Linear Models) para obtenção do teste $\mathrm{F}$ referente aos contrastes.

\section{RESULTADO E DISCUSSÃO}

Os dados de consumo médio diário por animal das misturas múltiplas, de proteína bruta (PB) e dos ingredientes nas fases das águas e seca são apresentados na Tabela 3.

O consumo médio diário por animal das misturas, dos ingredientes e de PB não foram analisados estatisticamente, uma vez que as medidas foram feitas por grupo de animais por tratamento e não individualmente.

A ingestão das misturas na fase das águas foi menor quando comparada com a fase seca, o que se deve à melhor qualidade da Brachiaria nas águas. O consumo de proteína bruta via mistura foi maior na fase seca, em que se pode observar menor porcentagem de $\mathrm{PB}$ na MS da Brachiaria e, conseqüentemente, uma necessidade maior de suplementação, quando comparado com a fase das águas.

O desempenho dos animais na fase das águas é apresentado na Tabela 4.

Não houve diferença entre os tratamentos para o ganho de peso e ganho de peso médio diário dos animais no período das águas.

Zervoudakis (2000) e Goes et al. (2000) não observaram diferença para o desempenho de bovinos suplementados em pasto no período das águas, mas observaram que os suplementos foram superiores $(\mathrm{P}<0,05)$ para o desempenho dos animais, quando comparados com um controle que recebeu apenas sal mineral.

Os dados relativos aos pesos iniciais e finais, ganho de peso e ganho de peso médio diário dos animais na fase seca encontram-se na Tabela 5.

Observou-se diferença $(\mathrm{P}<0,05)$ para ganho de peso e ganho de peso médio diário na fase seca, apesar de terem apresentados um alto coeficiente de variação.

TABELA 3 - Consumo das misturas múltiplas (g/animal/dia) nas fases das águas e seca.

\begin{tabular}{lcccc}
\hline & \multicolumn{4}{c}{ Tratamentos } \\
\cline { 2 - 5 } & AM-8,75 & UR-8,75 & AM-17,50 & UR-17,50 \\
\hline Mistura & \multicolumn{4}{c}{ Fase águas } \\
Amiréia & 140,33 & 110,72 & 110,34 & 118,82 \\
Uréia & 61,40 & & 38,62 & \\
Milho Moído & & 25,58 & 22,04 \\
N. Mineral & 42,10 & 55,14 & 33,10 & 54,36 \\
Sal & 24,56 & 19,38 & 19,31 & 20,79 \\
PB & 12,28 & 9,69 & 19,31 & 20,79 \\
& 96,31 & 77,13 & 61,24 & 67,13 \\
\hline Mistura & & & \\
Amiréía & 243,86 & 225,73 & 286,86 & 267,19 \\
Uréia & 106,69 & & 100,40 & \\
Milho Moído & & 52,14 & & 49,56 \\
N. Mineral & 73,16 & 112,41 & 86,06 & 122,24 \\
Sal & 42,68 & 39,50 & 50,20 & 46,76 \\
PB & 21,34 & 19,75 & 50,20 & 46,76 \\
\hline
\end{tabular}

Ciênc. agrotec., Lavras, v. 28, n. 1, p. 174-181, jan./fev., 2004 
TABELA 4 - Peso vivo inicial (PVI), peso vivo final (PVF), ganho de peso (GP), ganho de peso médio diário (GPMD) dos animais na fase das águas.

\begin{tabular}{cccccc}
\hline & \multicolumn{4}{c}{ Tratamentos } & CV (\%) \\
\cline { 2 - 4 } & AM-8,75 & UR-8,75 & AM-17,50 & UR-17,50 & \\
\hline PVI (Kg) & 196,90 & 199,60 & 195,60 & 195,20 \\
PVF (Kg) & 324,20 & 308,60 & 324,20 & 334,90 & 20,01 \\
GP (Kg) & 127,30 & 109,00 & 128,60 & 139,70 & 20,02 \\
GPMD (g) & 821 & 703 & 830 & 901 & \\
\hline
\end{tabular}

CV = coeficiente de variação.

TABELA 5 - Peso vivo inicial (PVI), peso vivo final (PVF), ganho de peso (GP), ganho de peso médio diário (GPMD) dos animais na fase seca.

\begin{tabular}{|c|c|c|c|c|c|}
\hline & \multicolumn{4}{|c|}{ Tratamentos } & \multirow{2}{*}{$\mathrm{CV}(\%)$} \\
\hline & AM-8,75 & UR-8,75 & AM-17,50 & UR-17,50 & \\
\hline PVI (Kg) & 288,09 & 284,70 & 276,73 & 287,18 & \\
\hline $\mathrm{PVF}(\mathrm{Kg})$ & 341,27 & 333,00 & 324,55 & 317,20 & \\
\hline $\mathrm{GP}(\mathrm{Kg})$ & 53,18 & 48,30 & 47,82 & 30,02 & 34,53 \\
\hline GPMD (g) & 719 & 653 & 647 & 406 & 34,53 \\
\hline
\end{tabular}

CV = coeficiente de variação.

Os contrastes para ganho de peso (GP) e ganho de peso médio diário (GPMD) entre os animais que receberam amiréia e os que receberam uréia com diferentes níveis de sal na fase seca são apresentados nas Tabelas 6 e 7, respectivamente.

TABELA 6 - Contrastes para GP $(\mathrm{Kg})$ entre os tratamentos na fase seca.

\begin{tabular}{ccc}
\hline Contrastes & Estimativa $(\mathbf{K g})$ & $\mathbf{P r}>\mathbf{F}$ \\
\hline $\mathrm{y}_{1}$ & 5,36 & 0,4498 \\
$\mathrm{y}_{2}$ & 18,28 & 0,0126 \\
$\mathrm{y}_{3}$ & 22,68 & 0,0264 \\
\hline
\end{tabular}

Pr $>\mathbf{F}=$ probabilidade de haver efeito significativo entre os tratamentos.
TABELA 7 - Contrastes para GPMD (g/animal/dia) entre os tratamentos na fase seca.

\begin{tabular}{ccc}
\hline Contrastes & $\begin{array}{c}\text { Estimativa } \\
\text { (g/anim./dia) }\end{array}$ & Pr $>\mathbf{F}$ \\
\hline $\mathrm{y}_{1}$ & 72 & 0,4497 \\
$\mathrm{y}_{2}$ & 247 & 0,0127 \\
$\mathrm{y}_{3}$ & 154 & 0,0264 \\
\hline
\end{tabular}

Pr $>\mathbf{F}=$ probabilidade de haver efeito significativo entre os tratamentos.

Não houve diferença de desempenho dos animais que receberam as misturas com amiréia nos dois níveis de sal $\left(\mathrm{y}_{1}\right)$.

Os animais que consumiram a mistura UR 8,75 apresentaram maiores ganhos de peso e ganhos de peso médio diário $(\mathrm{P}<0,05)$ quando comparados com os que 
consumiram a mistura UR 17,50 ( $\left.\mathrm{y}_{2}\right)$. Apesar de o consumo da mistura UR-17,50 ter sido superior ao consumo da mistura UR-8,75 pelos animais mantidos em campo (Tabela 3), o melhor desempenho dos que receberam UR-8,75 deve estar associado a um maior consumo de PB diário, quando comparado com UR-17,50.

Os animais que consumiram as misturas com amiréia apresentaram melhores desempenhos $(\mathrm{P}<0,05)$, quando comparados com os que receberam as misturas com uréia $\left(\mathrm{y}_{3}\right)$. De acordo com as observações de campo (Tabela 3), o consumo das misturas com amiréia pelos animais foram superiores e, conseqüentemente, esses consumiram mais PB diária do que os animais que receberam as misturas à base de uréia.

Helmer (1970b) e Maia et al. (1987) observaram que a liberação gradual da amônia proporcionou maiores concentrações $(\mathrm{mg} / 100 \mathrm{ml})$ de proteína microbiana e menores de amônia no fluido ruminal, o que pode ser conseqüência do aumento na eficiência dos microrganismos em usar a amiréia como substrato na produção de proteínas. Dessa forma, na fase seca, em que a qualidade do capim foi inferior à do das águas (Tabela 2), os melhores desempenhos dos animais que receberam misturas com amiréia podem ser explicados pelo maior crescimento microbiano promovido pela liberação gradual da amônia, além de promoverem uma sincronização entre a taxa de fermentação e a taxa de degradação da proteína (RUSSEL, 1992).

Os ganhos de peso e o ganho de peso médio diário (Tabela 5), elevados em todos os tratamentos para o período seco, podem ser justificados pela qualidade e disponibilidade de forragem (Tabela 2). Apesar de o consumo voluntário de animais em regime em pasto estar relacionado à disponibilidade de matéria seca da forragem, o consumo ou produção é função da disponibilidade de matéria seca proveniente de forragem verde (MANNETJE e EBERSOHN, 1980). Nesse sentido, a boa qualidade da pastagem e disponibilidade de MS/ha encontrado nos piquetes experimentais (Tabela 2) possivelmente possibilitou maior seletividade da forragem ingerida, propiciando, dessa forma, bons desempenhos.

\section{CONCLUSÃO}

No período das águas, os animais mestiços mantidos em piquetes de Brachiaria brizantha não apresentaram desempenhos diferentes entre os que consumiram as misturas com amiréia (150S) e uréia.

As misturas múltiplas com amiréia (150S) promoveram melhores desempenhos para os animais mes- tiços mantidos em pasto de Brachiaria brizantha no período seco.

\section{REFERÊNCIAS BIBLIOGRÁFICAS}

AGUIAR, A. P. A.; AMARAL, G. C. Metodologias de medição da pastagem para cálculo da taxa de lotação. In: ENCONTRO TERRA NOVA DE PECUÁRIA, 4., 2001, São José do Rio Preto. Anais... São José do Rio Preto: Terra Nova, 2001. p.15-30.

ANUÁRIO da Pecuária Brasileira. Rio de Janeiro: FNP, 2002. 400 p.

ASSOCIATION OF OFFICIAL ANALYTICAL CHEMIST. Official methods of the Assciation for Official Analytical Chemist. 15. ed. Washington, 1990. v. 1, 648 p.

BARTLEY, E. E.; DEYOE, C. E. Starea as a protein replaces for ruminants. FEEDSTUFS, Minneapolis, v. 47, n. 30, p. 42-44, 1975.

GOES, R. H. T. B.; MANCIO, A. B.; LANA, R. P. Desempenho de novilhos nelore em terminação à pasto recebendo, suplementação durante a época das águas. In: REUNIÃO ANUAL DA SOCIEDADE BRASILEIRA DE ZOOTECNIA, 37., 2000, Viçosa. Anais... Viçosa: SBZ, 2000. p. 389.

HELMER, L. G. Feed processing. IV: comparison of starea, urea and soybean meal as a protein sources for lactating dairy cows. Journal of Dairy Science, Champaing, v. 53, n. 7, p. 883-887, 1970a.

HELMER, L. G. Feed processing. V: effect of expansionprocessed mixture of grain and urea (Starea) on nitrogen utilization in vitro. Journal of Dairy Science, Champaing, v. 53, n. 3, p. 330-335, 1970 b.

MAIA, R. L. A.; TEIXEIRA, J. C.; PEREZ, J. R. O. Avaliação da qualidade da amiréia (produto da extrusão amido-uréia) através do método de estimativa da produção de proteína microbiana "in vitro". In: REUNIÃO DA SOCIEDADE BRASILEIRA DE ZOOTECNIA, 24., 1987, Brasília. Anais... Viçosa: SBZ, 1987. p. 95.

MANNETJE, L. T.; EBERSOHN, J. B. Relations between sward characteristics and animal production. Tropical Grasslands, Brisbane, v. 4, p. 273-280, Dec. 1980.

Ciênc. agrotec., Lavras, v. 28, n. 1, p. 174-181, jan./fev., 2004 
MHURER, M. E.; HARRIS, D. W.; BLOOMFIELD, R. A. Areacted NPN-carbohydrate complex grom urea. Journal of Animal Science, Champaing, v. 27, n. 6, p. 1770, 1986.

OWENS, F. N. Slow ammonia release from urea: rumen and metabolism studies. Journal of Animal Science, Champaing, v. 50, n. 3, p. 526-531, 1980.

PAULINO, M. F. Misturas múltiplas na nutrição de bovinos de corte a pasto. In: SIMPÓSIO GOIANO SOBRE PRODUÇÃO DE BOVINOS DE CORTE, 1., 1999, Goiânia. Anais... Goiânia: CBNA, 1999. p. 95-104.

RUSSEL, J. B. Minimização das perdas de nitrogênio pelos ruminantes. In: SIMPÓSIO INTERNACIONAL DE RUMINANTES, 1992, Lavras. Anais... Lavras: SBZ, 1992. p. 232-251.

SAS INSTITUTE. SAS user's guide: statistics. 5. ed. Cary, 1991. 1290 p.

SILVA, D. J. Análise de alimentos: métodos químicos e biológicos. 2. ed. Viçosa: UFV, 1998.165 p.
SOEST, P. J. van. Methods for dietary fiber, neutral detergent fiber and non-starch polysaccharides in relation to animal nutrition. Journal Dairy Science, Champaign, v. 74, p. 3583-3597, 1991.

STILES, D. A. Feed Processing VII: effect of an expansion-processed mesture of grain and urea (Starea) on rumen metabolism in cattle and urea toxicity. Journal of Dairy Science, Champaing, v. 53, n. 10, p. 1436-1447, 1970.

TEIXEIRA, J. C. Utilização da amirea 45-S (produto da extrusão amido-uréia) na alimentação de coelhos em crescimento, como fonte de nitrogênio em substituição parcial ao farelo de soja. In: REUNIÃO ANUAL DA SOCIEDADE BRASILEIRA DE ZOOTECNIA, 25., 1988, Brasília, DF. Anais...Viçosa: SBZ, 1987. p. 73.

ZERVOUDAKIS, J. T. Desempenho de novilhas mestiças suplementadas durante o período das águas. In: REUNIÃO ANUAL DA SOCIEDADE BRASILEIRA DE ZOOTECNIA, 37., 2000, Viçosa. Anais... Viçosa: SBZ, 2000. p. 388. 